\title{
DIREITOS FUNDAMENTAIS E A APLICAÇÃO DA PENA SEGUNDO O ESTATUTO DO ÍNDIO
}

\author{
Abner Pereira Matos \\ Graduando em Direito pela Universidade Federal do Rio Grande do Norte
}

\section{RESUMO}

A fim de verificar a efetividade da norma prevista no artigo $231 \mathrm{da}$ Constituição Federal no âmbito criminal, analisou-se os artigos $8^{\circ}, 9^{\circ} \mathrm{e}$ 10 da Convenção da Organização Internacional do Trabalho n. ${ }^{\circ} 169$, bem como os artigos 56 e 57 do Estatuto do Índio. Concluiu-se que o ordenamento jurídico brasileiro, reconhecendo os indígenas como um povo autônomo, impõe regras que devem ser observadas pelo juiz ao condenar penalmente o índio, de acordo com o seu grau de integração à sociedade civil. Tais regras consistem em se aplicar atenuante ao índio e em tolerar sanção anteriormente aplicada em desfavor do silvícola pela sua tribo, tratando-se essa última de hipótese excepcional, eis que afasta a jurisdição brasileira. Ademais, verificou-se que a jurisprudência brasileira se utiliza de elementos superficiais para determinar o grau de integração do índio, gerando, por conseguinte, presunção de culpabilidade.

Palavras-chave: Direitos fundamentais. Estatuto do índio. Direito penal. Dosimetria da pena.

\section{INTRODUÇÃO}

A Constituição Federal de 1998, tendo cunho altamente democrático e atendendo aos anseios de muitos setores sociais de interesses distintos, trouxe em seu bojo inúmeros direitos fundamentais, que não se esgotam no art. $5^{\circ}$, mas estão alastrados por todo o texto constitucional. Nesse contexto, o art. 231 prevê um direito fundamental específico destinado aos grupos indígenas que habitam o território nacional, reconhecendo sua autodeterminação. Além disso, a Lei n ${ }^{\circ}$ 6.001/73, o Estatuto do Índio, regula a situação jurídica dos índios de forma a preservar sua cultura e promover a sua integração à comunhão nacional, conforme o caso. 
A referida lei trata de diversos assuntos, mas o foco deste trabalho é a análise das disposições que regulam a aplicação da lei penal, visto que, como os indígenas possuem valores culturais diferentes dos da população não-indígena, seu modo de ser e agir são também diferentes. Em respeito a isso, até mesmo a aplicação da pena deve incorporar determinadas características de proteção aos silvícolas e à sua comunidade.

Sendo assim, pretende-se, primeiramente, através de pesquisas bibliográficas, mostrar em que medida o art. 231 da Constituição Federal é um direito fundamental garantido aos índios. Em segundo lugar, por meio do estudo da Convenção da Organização Internacional do Trabalho $\mathrm{n}^{\circ}$ 169, que traz algumas normas relacionadas à matéria aqui apresentada, almeja-se demonstrar a disciplina penal internacionalmente assentada em relação aos tribais. Por fim, mediante o exame da lei específica, o Estatuto do Índio, verificar-se-á como o ordenamento jurídico brasileiro trata da questão penal indígena de modo a concretizar a garantia trazida pelo art. 231 da Carta Magna. Para isso, o foco do estudo serão os arts. 56 e 57 do referido estatuto, os quais preveem princípios e normas penais, bem como alguns julgados jurisprudenciais, com o intuito de disciplinar a dosimetria da pena cominada aos índios.

\section{DOS DIREITOS FUNDAMENTAIS}

Por guardar estreita relação com a matéria a ser discutida, é interessante fazer breves considerações acerca dos direitos fundamentais. Preliminarmente, pode-se dizer que direito fundamental é aquele que tutela um bem básico e imprescindível aos seres humanos, quaisquer que sejam suas peculiaridades. Contudo, o tema é mais complexo do que aparenta.

Para Sarlet (2017), a fundamentalidade do um direito parte de aspectos formais e materiais. Do ponto de vista formal, é fundamental o direito que está integrado ao texto constitucional, gozando de privilégio hierárquico, isto é, supremacia frente a outras normas legais. Além disso, se fruto do constituinte derivado, os eventuais direitos fundamentais estão submetidos a determinados limites, a saber, o procedimento necessário à sua validade e as cláusulas pétreas.

Já do viés material, o conteúdo do direito fundamental deve orientar o comportamento do Estado e da sociedade, visando resguardar bens jurídicos imprescindíveis para a manutenção da vida digna. Com isso, o poder estatal é limitado, sendo-lhe exigida uma ação ou omissão apta a tutelar de forma efetiva o direito tido como fundamental. Da mesma forma, a liberdade 
dos particulares é cerceada, pois, desprovida de caráter absoluto, deve se adequar aos outros direitos fundamentais.

Fechando de modo mais objetivo o conceito de direito fundamental, Sarlet (2017) leciona que:

[...] é possível definir direitos fundamentais como todas as posições jurídicas concernentes às pessoas (naturais ou jurídicas, consideradas na perspectiva individual ou transindividual) que, do ponto de vista do direito constitucional positivo, foram, expressa ou implicitamente, integradas à constituição e retiradas da esfera de disponibilidade dos poderes constituídos, bem como todas as posições jurídicas que, por seu conteúdo e significado, possam lhes ser equiparadas, tendo, ou não, assento na constituição formal (2017, p. 350, grifos nossos).

Chama-se atenção ao trecho destacado da lição do autor, que indica que existem normas jurídicas infraconstitucionais capazes de serem equiparadas aos direitos fundamentais constitucionais por carregarem conteúdo e significado relativo a um bem jurídico relevante e indisponível. De fato, o art. $5^{\circ}, \S 2^{\circ}$, da Constituição, prevê que "os direitos e garantias expressos nesta Constituição não excluem outros decorrentes do regime e dos princípios por ela adotados, ou dos tratados internacionais em que a República Federativa do Brasil seja parte".

Como se lê, os direitos oriundos das normas constitucionais, ainda que não previstos na Carta Magna, terão caráter fundamental, pois carregam a fundamentalidade material, bem como serão fundamentais os direitos provenientes dos tratados internacionais ratificados pelo Estado brasileiro. Todavia, frise-se, o direito, seja infraconstitucional, seja internacional, somente poderá ser intitulado como fundamental se tal privilégio estiver disposto na Lei Maior.

\subsection{Dimensões dos direitos fundamentais}

Utilizando-se da construção doutrinária conhecida por "dimensões dos direitos fundamentais", existem, pacificamente, três dimensões de direitos fundamentais, subsistindo ainda teses que levantam uma quarta e até quinta geração. Não obstante, será utilizada a doutrina tripartida. Assim, a construção é didática, a fim de demonstrar as mudanças encarnadas pelos direitos fundamentais ao longo da história. Essas transformações sempre acompanham a ideia de Estado, bem como a sua atuação perante os sujeitos e também perante outros Estados.

A primeira dimensão diz respeito ao escopo dos direitos fundamentais no Estado Liberal, a saber, a proteção das liberdades individuais, exigindo-se, diante dessas, a omissão 
estatal. Assim, são direitos de resistência perante o Estado, sendo exemplos os direitos à propriedade, à expressão individual e coletiva, e à participação política.

A segunda geração está atrelada ao Estado Social, do qual se exigiu ação capaz de proporcionar bem-estar social à comunidade, através de prestações de saúde, educação e trabalho, por exemplo, conhecidas também por "liberdades sociais".

Por sua vez, a terceira geração interpreta o Estado por um viés comunitário, considerando-o partícipe da chamada sociedade internacional. Assim, a aplicação dos direitos fundamentais não se restringe às relações entre o Estado e seus cidadãos, mas atinge as relações estabelecidas entre os Estados e as relações firmadas entre estes e a humanidade: para a terceira geração, tanto a sociedade internacional como a humanidade são coletividades que possuem direitos fundamentais.

Sendo assim, os direitos fundamentais de terceira geração são metaindividuais por irem além da figura do indivíduo, alcançando uma coletividade. Assemelham-se aos direitos coletivos lato sensu, mais especificamente aos direitos difusos e coletivos, cujos conceitos se encontram no Código do Consumidor (art. 81). Resumidamente, estes são direitos indivisíveis cuja titularidade pertence a pessoas indeterminadas e ligadas por circunstâncias de fato (direitos difusos), ou a um grupo, categoria ou classe de pessoas ligadas entre si (direitos coletivos stricto sensu).

Portanto, trata-se de tutela jurídica eminentemente internacional, abrangendo o alcance dos direitos fundamentais, de forma a abraçar a humanidade em geral, bem como os povos que lhe integram. São exemplos de direitos fundamentais de terceira dimensão o direito à paz, à autodeterminação dos povos e ao meio ambiente. Sobre o tema, aduz Sarlet (2017) o seguinte:

Os direitos fundamentais da terceira dimensão, também denominados direitos de fraternidade ou de solidariedade, trazem como nota distintiva o fato de se desprenderem, em princípio, da figura do homem-indivíduo como seu titular, destinando-se à proteção de grupos humanos (povo, nação), caracterizando-se, consequentemente, como direitos de titularidade transindividual (coletiva ou difusa). Para outros, os direitos da terceira dimensão têm por destinatário precípuo "o gênero humano mesmo, num momento expressivo de sua afirmação como valor supremo em termos de existencialidade concreta". Dentre os direitos fundamentais da terceira dimensão mais citados, cumpre referir os direitos à paz, à autodeterminação dos povos, ao desenvolvimento, ao meio ambiente e qualidade de vida, bem como o direito à conservação e utilização do patrimônio histórico e cultural e o direito de comunicação (p. 343). 
No cenário internacional, impende sobrelevar a Convenção nº 169 da OIT, que foi ratificada pelo Brasil e passou a possuir caráter supralegal no ordenamento pátrio. A Convenção, que trata sobre os Povos Indígenas e Tribais, trouxe proteção específica aos índios, já que outros diplomas, como a Declaração Universal de Direitos Humanos de 1945, não davam o devido cuidado aos direitos indígenas, nem às suas peculiaridades, mas somente os reconheciam indiretamente ao erigir direitos pertencentes a "todos os seres humanos".

As normas que importam ser mencionadas estão previstas nos arts. $8^{\circ}, 9^{\circ}$ e 10 . Por elas, tem-se que:

\footnotetext{
Artigo 8은

1.Ao aplicar a legislação nacional aos povos interessados deverão ser levados na devida consideração seus costumes ou seu direito consuetudinário.

2.Esses povos deverão ter o direito de conservar seus costumes e instituições próprias, desde que eles não sejam incompatíveis com os direitos fundamentais definidos pelo sistema jurídico nacional nem com os direitos humanos internacionalmente reconhecidos. Sempre que for necessário, deverão ser estabelecidos procedimentos para se solucionar os conflitos que possam surgir na aplicação deste princípio.

3.A aplicação dos parágrafos 1 e 2 deste Artigo não deverá impedir que os membros desses povos exerçam os direitos reconhecidos para todos os cidadãos do país e assumam as obrigações correspondentes.

Artigo 9을

1.Na medida em que isso for compatível com o sistema jurídico nacional e com os direitos humanos internacionalmente reconhecidos, deverão ser respeitados os métodos aos quais os povos interessados recorrem tradicionalmente para a repressão dos delitos cometidos pelos seus membros.

2.As autoridades e os tribunais solicitados para se pronunciarem sobre questões penais deverão levar em conta os costumes dos povos mencionados a respeito do assunto.

Artigo 10

1.Quando sanções penais sejam impostas pela legislação geral a membros dos povos mencionados, deverão ser levadas em conta as suas características econômicas, sociais e culturais.

2.Dever-se-á dar preferência a tipos de punição outros que o encarceramento.
}

Da leitura, é possível estabelecer três parâmetros de aplicação da lei nacional aos indígenas: a) a necessidade de serem observados seus costumes e direito consuetudinário, que serão preservados enquanto compatíveis com os demais direitos fundamentais; b) o respeito aos métodos repressivos penais utilizados por esses povos, desde que a sanção utilizada faça parte dos costumes da tribo; c) a adequação da pena deverá observar as características econômicas, sociais e culturais do índio infrator.

Assim, o primeiro parâmetro tem aplicação geral, podendo ser observado em qualquer esfera do direito. Os outros dois parâmetros têm aplicação específica na seara penal, dizendo respeito à tolerância, pelo Estado, das sanções impostas pela comunidade tribal, bem como da individualização da pena, que levará em conta as características intrínsecas ao silvícola infrator. 


\section{DISCIPLINA CONSTITUCIONAL E CLASSIFICAÇÃO DO DIREITO FUNDAMENTAL INDÍGENA PREVISTO NO ARTIGo 231 DA CONSITUIÇÃo FEDERAL}

Quanto à tutela jurídica concernente aos índios, o art. 231, caput, da Constituição Federal, assim dispõe:

Art. 231. São reconhecidos aos índios sua organização social, costumes, línguas, crenças e tradições, e os direitos originários sobre as terras que tradicionalmente ocupam, competindo à União demarcá-las, proteger e fazer respeitar todos os seus bens.

Trata-se de um direito fundamental, pois está previsto no texto da Lei Maior e defende bem básico necessário ao ser humano, limitando a postura do Estado e até mesmo dos particulares. É direito difuso, pois remete aos interesses de um povo, uma coletividade de indivíduos ligados pelas mesmas crenças, línguas, organização, costumes, enfim, pelos mesmos sentimentos. Sendo assim, trata-se de direito fundamental de terceira geração, porque busca garantir a autodeterminação dos povos indígenas, isto é, a liberdade e poder efetivo de se autogovernar e ser independente.

Nesse compasso, o dispositivo constitucional apresenta proteção a direitos imateriais e materiais, quando, respectivamente, abarca o "modo de vida dos indígenas", e apresenta disciplina específica quanto às terras ocupadas pelos índios. Inclusive, neste segundo ponto, a Constituição é mais extensa, apresentando regras intrínsecas à tutela das terras. É assim porque é bem sabido que os índios foram alvo de constantes explorações, principalmente em relação aos espaços geográficos ocupados por eles. Diante disso, e por ter o constituinte reconhecido que as terras constituem suporte material necessário ao desenvolvimento das comunidades indígenas, háregras constitucionais específicaspara esta matéria.

Contudo, ainda que essa proteção seja mais extensa, os direitos imateriais abraçados pelo art. 231 não são menos importantes. Se assim fosse, tratar-se-ia de verdadeiro retrocessojurídico, pois a tutela seria apenas formal, viabilizando ofensas à dignidade humanados indígenas. 


\section{O ESTATUTO DO ÍNDIO}

Como bem ressaltado, o art. $5^{\circ}, \S 2^{\circ}$, da Constituição Federal permite que direitos infraconstitucionais ostentem a primazia dos direitos fundamentais, desde que decorram dos princípios e normas constitucionais e tenham como núcleo a proteção de direito básico e indisponível, relevante para a vida humana. Nesse sentido, a Lei $n^{\circ} 6.001 / 73$, que dispõe sobre o Estatuto do Índio, traz em seu bojo direitos fundamentais, pois significou expressiva proteção a direitos básicos e indisponíveis dos povos indígenas.

Entretanto, por ser de 1973, o diploma está defasado. Houve iniciativa, no Congresso Nacional, de atualizar a lei através do Projeto de Lei n².057/1991 (Estatuto das Sociedades Indígenas), que ainda não apresentou avanço significativo. Da mesma forma, o Projeto de Lei $n^{\circ} 169 / 2016$ visa modificar o Estatuto, trazendo regramento muito mais complexo que atende as necessidades atuais dos tribais. Percebe-se, contudo, que a questão indígena está atrelada diretamente a questões políticas, sobremaneira quando se trata das terras ocupadas pelos silvícolas. Nesse passo, a bancada ruralista vem demonstrando firme resistência a qualquer tentativa de avanço acerca da matéria.

\subsection{Quem é o índio}

É fundamental esclarecer o conceito de índio e identificar quem pode defini-lo antes de adentrarmos na questão do tratamento penal aos indígenas, posto que somente mediante essa prévia definição será possível observar se o Direito está servindo de forma adequada aos seus titulares.

O Estatuto define como índio aquele que possui ascendência com o grupo étnico indígena, se reconhece como índio e é identificado pelo grupo como tal. Com efeito, a Fundação Nacional do Índio (FUNAI) explica em seu site oficial que o reconhecimento do indivíduo como silvícola se dá mediante a observação de dois requisitos, quais sejam: a autodeclaração e a consciência de sua identidade indígena e o reconhecimento dessa identidade por parte do grupo de origem. O diploma em exame também estabelece uma gradação da caracterização silvícola conforme a sua integração na sociedade, definindo o índio como isolado, em vias de integração e integrado, o que será estudado posteriormente, em tópico próprio.

\subsection{Das normas penais aplicáveis aos indígenas}


Como dito, baseado no art. 231, da CF, o presente estudo está focado em apresentar a disciplina penal dos indígenas. Embora haja, no Estatuto, disciplina legal específica aos tribais, o STF já se posicionou acerca da possibilidade de ser aplicado ao índio o art. 26 do Código Penal, que versa sobre a inimputabilidade, desde que seja evidente que o índio não possuía, à época dos fatos, consciência da ilicitude do crime cometido, isto é, o instituto pode ser afastado caso seja manifesta a compreensão do silvícola acerca da infração penal. Não sendo o caso de incidência do art. 26 do Código Penal, aplica-se o Estatuto do Índio, que prevê, nos arts. 56 e 57, a forma com que as normas penais serão aplicadas aos indígenas, através do teor abaixo transcrito:

\footnotetext{
Art. 56. No caso de condenação de índio por infração penal, a pena deverá ser atenuada e na sua aplicação o Juiz atenderá também ao grau de integração do silvícola. Parágrafo único. As penas de reclusão e de detenção serão cumpridas, se possível, em regime especial de semiliberdade, no local de funcionamento do órgão federal de assistência aos índios mais próximos da habitação do condenado.

Art. 57. Será tolerada a aplicação, pelos grupos tribais, de acordo com as instituições próprias, de sanções penais ou disciplinares contra os seus membros, desde que não revistam caráter cruel ou infamante, proibida em qualquer caso a pena de morte.
}

Da leitura percebe-se que existem duas regras aplicáveis aos indígenas, caso estes pratiquem algum ilícito penal. Conforme o art. 56, o juiz aplicará ao índio criminoso uma atenuante, atendendo também ao seu grau de integração à sociedade, em acordo com a gradação do art. $4^{\circ}$, a qual será estudada em tópico específico.

Então, tem-se duas peculiaridades na aplicação da pena aos indígenas, a saber, o seu grau de integração à sociedade e uma atenuante. A primeira corresponde a uma circunstância judicial, objeto da primeira fase da aplicação da pena (art. 59 do Código Penal). Assim, na primeira fase da dosimetria da pena, será verificado o grau de integração do silvícola à sociedade, conforme art. $4^{\circ}$ do Estatuto. A segunda peculiaridade é uma atenuante, nos moldes do art. 65do Código Penal, a ser avaliada na segunda fase da dosimetria da pena.

\subsubsection{Considerações sobre a aplicação da atenuantede pena}

A atenuante, segundo posicionamento do STJ, somente se aplica aos índios em fase de aculturação, isto é, aos que estão em vias de integração à sociedade. Nesse contexto, a Corte considera o índio nativo como aquele que, distante da sociedade civil, não possui nenhum discernimento sobre a ilicitude do crime. Se assim for, quanto aos crimes, aplica-se o art. 26 do 
Código Penal. Mas se o indígena já adentrou em processo de integração, participando da comunhão nacional, então adquiriu alguma noção do que é ilícito. É nesse caso, conforme entendimento da Corte, que a atenuante do art. 56 poderá ser aplicada. Por outro lado, se totalmente integrado, o indígena já está apto a discernir, sendo inviável lhe aplicar a atenuante ora discutida.

Além disso, consoante a tese vencedora do Habeas Corpus $\mathrm{n}^{\circ}$ 88.853/MS, baseada na interpretação sistemática, entendeu-se que o diploma de defesa dos silvícolas tem o propósito de preservar-lhes a cultura e integrá-los, progressiva e harmoniosamente, à cultura nacional, e, por isso, suas disposições dizem respeito somente ao índio em vias de integração. Diante disso, importa fazer breves esclarecimentos.

$\mathrm{O}$ art. 56 do Estatuto do Índio determina a aplicação de atenuante aos índios que cometeram crime. A princípio, não se trata de avaliar o grau de integração, mas somente de considerar a condição de indígena. Nisso, percebe-se o valor da norma contida neste dispositivo, a saber, o reconhecimento de que o povo indígena possui estrutura organizacional, cultura e tradições próprias, isto é, de que a comunidade tribal está fincada em valores diversos da sociedade civil, e por isso, terá concepções e modo de vida diferentes, que muitas vezes poderão se chocar com a realidade da sociedade civil. Em suma, é o reconhecimento da autodeterminação dos indígenas. Tendo em vista esses motivos, a aplicação da pena sobre o índio é justificadamente diferenciada.

Apesar de não se tratar de averiguar o grau de integração, mas de considerar a condição de indígena, o nível de comunhão que o silvícola tem com a sociedade irá influenciar a aplicação da atenuante, pois a medida desta não será a mesma para todos os casos, em respeito ao princípio da individualização da pena. Assim, o juiz deverá lançar mão dos graus de integração previstos no art. $4^{\circ}$ do Estatuto do Índio.

Agora, na contramão do que foi exposto, ainda que a atenuante tenha sido determinada expressamente, configurando uma garantia ao índio, ela não pode ser aplicada de forma absoluta. Como dito, a medida da atenuação variará de acordo com o grau de integração, mantendo-se entre elas proporcionalidade inversa. Sendo assim, quanto menor o grau, maior a atenuante, e quanto maior o grau, menor será a atenuação.

Todavia, haverá casos em que o grau de integração do índio é tão alto que a aplicação da atenuante não mais se justifica. Isso porque o indígena efetivamente integrado já absorveu a cultura nacional e, mesmo preservando seus usos e costumes, possui plena consciência do que a sociedade civil considera como lícito e ilícito. Dessa forma, mesmo tendo origem indígena, se realmente integrado, o indivíduo tem discernimento equiparável ao de um sujeito civil 
comum e, nessa situação, a aplicação da atenuante acarretaria verdadeira ofensa ao princípio da igualdade, haja vista que os motivos que justificam a diferenciação não mais prevalecem.

Dessa forma, conclui-se que a jurisprudência entendeu corretamente, restringindo a aplicação da atenuante aos índios em vias de integração. É o que se depreende dos julgados abaixo colacionados:

\begin{abstract}
AGRAVO REGIMENTAL NO RECURSO ORDINÁRIO EM HABEAS CORPUS. REGIME PRISIONAL SEMIABERTO. LEI N. 6.001/1973 (ESTATUTO DO ÍNDIO). INDÍGENA INTEGRADO À SOCIEDADE. IMPOSSIBILIDADE. 1. A pretendida aplicação da atenuante de que cuida o art. 56, parágrafo único, da Lei n. 6.001/1973 somente tem incidência ao indígena não integrado socialmente, não assim àquele já incorporado à comunhão nacional e no pleno exercício dos seus direitos civis, ainda que conserve usos, costumes e tradições características de sua cultura. 2. Agravo regimental a que se nega provimento (AGRRHC - Agravo Regimental no Recurso Ordinário em Habeas Corpus - 79210 2016.03.17271-5, Min. Antônio Saldanha Palheiro, STJ - sexta turma, Dje: 20/04/2017).
\end{abstract}

AGRAVO REGIMENTAL EM RECURSO ESPECIAL. PENAL. CRIME DE INCÊNDIO. INDÍGENA INTEGRADO À SOCIEDADE BRASILEIRA. PLEITO DE APLICAÇÃO DA ATENUANTE DO ART. 56, PARÁGRAFO ÚNICO, DA LEI 6.001/73. IMPOSSIBILIDADE. 1. Este Tribunal Superior possui entendimento firmado de que o art. 56, parágrafo único, da Lei ${ }^{\circ}$ 6.001/76 (Estatuto do Índio), a embasar a pretensão de atenuação da reprimenda, somente se destina à proteção do silvícola não integrado à comunhão nacional; ou seja, esse dispositivo legal não pode ser aplicado em favor do indígena já adaptado à sociedade brasileira. 2. Agravo regimental a que se nega provimento (AGRESP - Agravo Regimental no Recurso Especial - 1361948 2013.00.14632-7, Marco Aurélio Bellizze, STJ - quinta turma, Dje:16/09/2013).

\title{
5.2.2 Considerações sobre os graus de integraçãodo índio à sociedade
}

Outra observação a ser feita diz respeito aos graus de integração previstos no art. $4^{\circ}$ do Estatuto do Índio. Assim dispõe a lei:

Art. $4^{\circ}$ Os índios são considerados:

I - Isolados - Quando vivem em grupos desconhecidos ou de que se possuem poucos e vagos informes através de contatos eventuais com elementos da comunhão nacional; II - Em vias de integração - Quando, em contato intermitente ou permanente com grupos estranhos, conservam menor ou maior parte das condições de sua vida nativa, mas aceitam algumas práticas e modos de existência comuns aos demais setores da comunhão nacional, da qual vão necessitando cada vez mais para o próprio sustento; III - Integrados - Quando incorporados à comunhão nacional e reconhecidos no pleno exercício dos direitos civis, ainda que conservem usos, costumes e tradições característicos da sua cultura.

O problema mais evidente dos critérios acima expostos é que são demasiadamente superficiais, dando lugar a interpretações equivocadas. De fato, em alguns casos, a jurisprudência entende que a presença de documentação civil, carteira profissional, aparelho 
celular, título de eleitor, fluência na língua portuguesa, posse de veículo automotor e participação em jogos de futebol na comunidade são suficientes para qualificar o índio como integrado, sendo ainda permitido afastar a perícia antropológica para aferir a imputabilidade penal com base nesses elementos. Eis um exemplo:

\footnotetext{
Havendo prova inequívoca de ser o índio completamente integrado na civilização, sendo eleitor, habilitado para dirigir veículo, operador em instituição financeira, pode o Juiz prescindir do laudo antropológico para aferir a imputabilidade penal. (HC 9.403/PA, Rel. Ministro JOSÉ ARNALDO DA FONSECA, QUINTA TURMA, julgado em 16/09/1999, DJ 18/10/1999, p. 242).
}

Todavia, ressaltou-se que as disposições estatutárias partem do reconhecimento de que os tribais possuem uma consciência e discernimentos próprios, formados através da cultura e tradições indígenas, e que essa consciência difere da consciência da sociedade civil.

Dessa forma, os graus de integração refletem o quanto de "consciência civil" o índio absorveu, de modo a compreender os valores nacionais e discernir o que se entende por ilícito. Índios nativos são aqueles que preservam sua consciência integralmente; índios em vias de integração são aqueles que estão em processo de aprendizagem, assimilando alguns fatores da cultura nacional; e índios integrados são aqueles que absorveram com propriedade a sobredita "consciência civil".

Isso não quer dizer que quanto maior for a integração, mais o indígena "deixa de ser índio". A condição de indígena permanece inalterada. Afirma-se que o silvícola adquiriu, cumulativamente, outra consciência, a da sociedade civil. Por ser assim, fica claro que possuir título de eleitor, carteira de identidade ou participar de um jogo de futebol não são elementos que manifestam o grau de integração do silvícola.

Outro problema identificado na disciplina da integração é sua incompatibilidade com os princípios penais, processuais penais e também de outros ramos do direito, visto que o texto legal peca pelo excesso de formalidade. Sabe-se que, no processo penal, vigora o princípio da busca pela verdade material. Segundo este princípio, o juízo deve investigar de forma a se aproximar da veracidade dos fatos e se apropriar das reais nuances da situação, a fim de proferir uma decisão adequada, já que os bens jurídicos em jogo são indisponíveis.

Assim, enfatiza-se, considerar elementos tão rasos para aferir o grau de integração do índio à sociedade causa grande prejuízo à tutela da autodeterminação indígena, pois aqueles elementos não traduzem, de fato, o quanto o indígena absorveu da cultura nacional, ou se esta foi mesmo absorvida. 
Somado a isso, não se preocupando com a profundidade que os graus de integração carregam, mas se limitando a aplicar o simples texto legal e a posição majoritária das Cortes, surge outra controvérsia: o desprezo ao princípio da individualização da pena e da vedação à presunção de culpabilidade. Isso porque, frise-se, os elementos de distinção consagrados jurisprudencialmente não traduzem, de fato, o verdadeiro grau de integração do índio. Então, torna-se possível que silvícolas com diferentes níveis de absorção da cultura nacional sejam classificados com o mesmo grau de integração por possuírem, por exemplo, documentos civis, e, assim, sejam tratados como iguais fossem.

Pelos mesmos motivos, indiretamente, tem-se verdadeira presunção de culpabilidade, pois, através da mera existência daqueles elementos fúteis já citados, presume-se, sem se investigar seu grau de integração à sociedade civil, que o índio tem consciência sobre o ilícito cometido, sendo por isso culpável de plano.

\subsubsection{Do laudo antropológicopara aferir a imputabilidade penal do índio}

Não se pretende demonizar os graus de integração dos indígenas à sociedade, previstos no art. $4^{\circ}$ do Estatuto do Índio. Pelo contrário, esses artifícios foram disponibilizados de modo a orientar a atuação do juiz no momento da dosimetria da pena. O que se critica aqui é a forma como o dispositivo legal é interpretado e os meios utilizados para aferir o referido grau de integração. Mediante orientação posta pelo legislador, e em conjunto com as demais provas juntadas ao processo, o julgador decidirá em que grau de integração o silvícola se encontra. Caso não seja possível determinar isso, aplica-se o que for mais benéfico ao réu.

Nesse diapasão, ainda que não haja prova absoluta no Direito brasileiro, o laudo antropológico, muitas vezes afastado pelo juiz, se mostra como o meio mais adequado para medir o real grau de integração do tribal, bem como sua consciência acerca da ilicitude, visto que se utiliza de metodologia complexa a fim de demonstrar as idiossincrasias de determinado grupo, no caso, os indígenas, de forma a entendê-los como tal. Conforme lições de Luciano Mariz Maia, vice procurador da República:

Aplicada ao Direito, a perícia antropológica é responsável pela identificação de um grupo étnico enquanto tal (índios, quilombolas, ciganos, gerazeiros, populações tradicionais, etc.); pela revelação de seus usos, costumes, tradições, modos de ser, viver, se expressar; pela documentação de sua memória e sua ação (reconstruindo sua trajetória de luta e de vida, de resistências e transformações, de deslocamentos e perdas, de insurgências e ressurgências); delimitação de seu território e de espaços de interação com o meio ambiente ou outras comunidades intraétnicas ou interétnicas (nisso indicando a finalidade prática da identificação da ocupação tradicional). Tudo 


\begin{abstract}
isso para assistir o juiz em seu processo decisório. [...] Um campo em que o antropólogo também atua, com particular relevância, na seara jurídica, é o da identificação das condições pessoais, subjetivas, de capacidade penal, ou seja, consciência do caráter ilícito da conduta praticada pelo membro de uma etnia, normalmente por um indígena. Nesse campo o jurista ainda tem sido muito autossuficiente, e deficiente na formação de seu entendimento, por valorizar alguns aspectos que dizem menos do que se esperava dissessem. Em geral, por prudência, e para desincumbir-se adequadamente do dever de realizar a defesa dos direitos dos índios no campo penal, o Ministério Público Federal, quando há ação penal contra indígenas, identifica necessidade de realização de perícia antropológica, para documentar o grau de compreensão que o suspeito ou acusado tem do caráter ilícito e culpável de sua conduta (2013 ou 2014, p. 2, 16)
\end{abstract}

Assim, não se olvida da possibilidade de o laudo ser afastado, em detrimento de outras provas. Todavia, pelo exposto, os elementos externos à comunidade indígenas utilizados para determinar o grau de integração são demasiadamente inadequados, por serem superficiais e não transmitirem, materialmente, a complexidade e riqueza da cultura tribal, sendo o laudo em questão o meio mais fidedigno à averiguação desses elementos.

\title{
5.2.3 Sobre a tolerância prevista no art. 57 do Estatuto do Índio
}

O art. 57 obriga o juiz a tolerar aplicação de sanções penais e disciplinares próprias da comunidade aborígene, salvo se forem cruéis, infamantes ou de morte. Aqui, salienta-se que, para haver total consonância com a Constituição, deve ser considerado o inciso XLVII, do art. $5^{\circ}$, que veda, além das penas cruéis e de morte, penas de caráter perpétuo, trabalhos forçados e banimento.

Para ilustrar a regra acima destacada, em 2016, o Direito brasileiro se deparou com caso inédito, no qual foi aplicado o instituto da tolerância previsto no art. 57 do Estatuto do Índio. Trata-se da Apelação Criminal n 0090.10.000302-0 - TJ-RR, na qual um índio da terra Manoá-Pium, na reserva Raposa Serra da Lua, no Estado de Roraima, foi denunciado pelo Ministério Público pela prática do crime de homicídio simples, previsto no art. 121 do Código Penal, contra outro índio. Em defesa do indígena, a Fundação Nacional do Índio (FUNAI), a Advocacia-Geral da União (AGU) e Procuradorias Federais do Estado (PF/RR) ingressaram no feito como partes interessadas, fundamentando-se no instituto da tolerância previsto no art. 57 do Estatuto do Índio. Para a defesa, o direito consuetudinário deve prevalecer, pois, como o réu já havia sido punido pela sua tribo, condenação penal acarretaria em bis in idem.

O tribunal acatou a defesa apresentada, aplicando o art. 57e afastando a condenação penal, pois ficou evidenciado que, baseado na autoridade e costumes da comunidade tribal, o indígena infrator foi punido com o afastamento de sua comunidade por cinco anos, devendo, 
nesse período, sob custódia da tribo WaiWai, comercializar somente com autorização e prestar serviços comunitários às tribos vizinhas, bem como aprender os usos, costumes e língua dos WaiWai, além de ter-lhe sido imposto a obrigação de construir uma casa à esposa da vítima e não se ausentar do território indígena sem a permissão da tribo.

\section{CONCLUSÕES}

Viu-se que o art. 231 da Constituição Federal trazum direito fundamental por excelência, tanto em seu aspecto formal, quanto material, pois, além de estar previsto no texto contitucional, resguarda direito intrínseco e necessário à manutenção da dignidade indígena, imponto o reconhecimento de sua cultura e organização social. Somado a isso, a norma fundamental abrangeoutro direito ainda maior, considerado de terceira geração: o direito à autodeterminação indígena. Assim, este grupo é considerado um povo autônomo, passível de organizar suas estruturas internas e ser respeitado pelos demais povos.

Agora, no plano infraconstitucional, percebe-se que o Estatuto do Índio traz regras peculiares, quando os arts. 56 e 57 preveem, respectivamente, uma atenuante a ser aplicada ao índio criminoso, bem como o dever de tolerar a aplicação de sanções próprias dos grupos tribais.

Pela atenuante, chegou-se ao entendimento de que a jurisprudência não está totalmente correta, pois, apesar de afastar a aplicação da regra aos silvícolas integrados em respeito ao princípio da igualdade, ao utilizar os graus de integração previstos no art. $4^{\circ}$, as Cortes acabaram por indiretamente criar uma presunção de culpabilidade, considerandoque os índios nativos sempre serão inimputáveis e que os indígenas integrados possuem total consciência dos costumes da comunidade nacional. Ainda, os meios utilizados para aferir o nível de consciência do índio são em demasiado superficiais, dado que se resumem àverificação de meros elementos externos que em nada traduzem o quanto o índio entende o caráter ilícito do crime, ou o quanto o ele absorveu da cultura nacional.

Essa tese firmada jurisprudencialmente fere princípios penais, processuais penais e constitucionais, eis que o ordenamento jurídico brasileiro não admite preseunção de culpabilidade na esfera penal nem inobservância à individualização da pena. Assim, em respeito à busca da verdade real, o julgador deve verificar o quanto o silvícola realmente está integrado à sociedade comum, visando aplicar a sanção mais adequada a cada caso concreto. Para isso, o laudo antropológico indígena se mostra a prova mais robusta. 
Quanto ao dever de tolerancia estabelecido noart. 57, percebe-se que o juiz, ao aplicar a pena, deve verificar se há condenação tribal anterior, se esta é medida costumeira e se está adequada aos demais direitos fundamentais. Em caso positivo, aquela condenação deverá ser tolerada, tratando-se de verdadeira exceção no ordenamento jurídico brasileiro, já que sentenciar o indígena condenado pela tribo acarretaria bis in idem. Por outro lado, em caso negativo, aplica-se o art. 56 do Estatuto, adequando a pena de acordo com o grau de integração do índio e atenuando-a se não se tratar de índio totalmente integrado.

Por fim, de todo o exposto, está luminoso que as disposições constitucionais e infraconstitucionais aqui abordadas estão em connsonância com os parâmetros elencados pela Convenção 169 da OIT, reconhecendo-se os costumes tribais, bem como seus métodos repressivos, e considerando suas peculiaridades ao se aplicar a lei penal.

\section{REFERÊNCIAS}

BRASIL. Constituição da República Federativa do Brasil de 1998. Disponível em: <http://www.planalto.gov.br/ccivil_03/constituicao/constituicaocompilado.htm>.Acesso em: 06 maio 2018.

.Decreto $\mathbf{n}^{\mathbf{0}}$ 5.051, de 19 de abril de 2004. Promulga a Convenção $\mathrm{n}^{\circ} 169$ da Organização Internacional do Trabalho - OIT sobre Povos Indígenas e Tribais. Disponível em: <http://www.planalto.gov.br/ccivil_03/_ato2004-2006/2004/decreto/d5051.htm>. Acesso em: 10 jun. 2018.

.Lei $\mathbf{n}^{0}$ 6.001, de dezembro de 1973. Dispõe sobre o Estatuto do Índio. Disponível em: <http://www.planalto.gov.br/ccivil_03/leis/L6001.htm>.Acesso em: 10 jun. 2018.

MAIA, Luciano Mariz. Do papel da perícia antropológica na afirmação dos direitos dos índios. Disponível em: <http://www.mpf.mp.br/atuacao-tematica/ccr6/documentos-epublicacoes/artigos/docs_artigos/do_papel_da_pericia_antropologica_na_afirmacao_dos_dire itos_dos_indios.pdf >. Acesso em: 10 jun. 2018.

SARLET, Ingo Wolfgang; MARINONI, Luiz Guilherme; MITIDIERO, Daniel. Curso de Direito Constitucional. 6 ed. São Paulo: Saraiva, 2017. 


\title{
FUNDAMENTAL RIGHTS AND PENALTY ACCORDING TO BRAZILIAN INDIGENOUS STATUTE
}

\begin{abstract}
In order to verify the effectiveness of the article 231 of Brazilian Federal Constitution on the criminal scope, this article analyzes the articles 8, 9 and 10 of Indigenous and Tribal Peoples Convention, 1989 (No. 169), as well as the articles 56 e 57 of Brazilian Indigenous Statute. The analysys came to the conclusion that brazilian legal system acknowledges that indigenous people have autonomy and imposes rules that must me observed by the judge in the moment of crimnal conviction according to the indigenous' degree of integration with civil society. Those rules consist in mitigating the penalty and tolerating the punishment previously applied by the indigenous' tribe -- an exceptional hypothesys in wich the brazilian jurisdiction is put away. Thus, it was verified that brazilian jurisprudence uses superficial elements to determine the indigenous' integration degree to society, assuming his culpability.
\end{abstract}

Keywords: Fundamental rights. Brazilian Indigenous Statute. Criminal law. Penalty dosimetry. 